of the characteristic tabular crystals of cholesterin. The cerebellum and medulla were slightly depressed for the reception of the mass.

CASE II.-This case occurred in our practice some time ago, and it is mentioned here on account of the symptoms having been similar, although the brain lesion had a different situation. The animal was a six-years-old cart horse which had to be destroyed after exhibiting symptoms of loss of power and want of co-ordination. These symptoms were more pronounced than in the previous case, and ultimately the horse was unable to rise. After death the cause of these symptoms was found to be an inward bulging of the cranial vault, brought about by the development of a serous abscess in the temporal fossa.

\title{
PARALYSIS IN HORSES FED ON PEA STRAW.
}

By Thomas Campbell, M.R.C.V.S., Kirby-Moorside, Yorkshire.

ON the 4th of March last I was called to a farm in this district, to see some horses that appeared to be partially paralysed. On my arrival I found that one of the animals-a bay pregnant mare-showed distinct indications of loss of power in the hind quarters, and several others were affected in the same way but to a less degree. The inability in each case was manifested by a most noticeable side-to-side swaying motion when the animal walked. The temperature and respirations were found to be normal, but the pulse was rather slow34 per minute in the mare. The appetite, I was informed, was good.

My thoughts were naturally directed towards the food and water; inquiry appeared to show that the water could not be incriminated, but I ascertained that the character of the food was at least open to suspicion. The horses had for some time been fed exclusively on unthrashed pea straw cut into chaff, and inspection showed that this was of inferior quality and contained a considerable quantity of sand, or loam.

Coming to the conclusion that the food was at fault, I ordered an entire change, stopping the pea chaff and substituting oats and hay, with oatmeal gruel to drink. At the same time I administered a mild aperient to the mare.

On the following day (5th March) I found the pregnant mare down, unable to regain her feet, and tympanitic. The temperature was normal, and the pulse and respirations were a little acceleratedapparently as the result of struggling. The bladder was full, and had to be emptied by means of the catheter. The condition of the other animals remained unaltered.

6th March.-Mare still unable to rise, appetite good, catheter had again to be used. I found that one of the horses appeared to have lost the contractile power of the rectum, and ordered enemata, a little belladonna being added to each. I also prescribed nux vomica and sulphate of iron, to be given twice daily with the food.

$7_{\text {th }}$ March.-Condition of animals unaltered. Bay mare put in slings.

8th March--On this date a black mare and a black gelding were found to be down and unable to rise. 
9th March.-Black mare found dead. The post-mortem examination showed nothing to account for death.

roth March.-Bay mare in slings foaled a dead foal in the morning, and later in the day she was able to walk to a loose box close by. In the evening the mare was found down and unable to rise, and she was again put into slings. An attempt was made to sling the black gelding also, but this failed, and he died the same night. The postmortem in this case also gave negative results; portions of the viscera were sent to Professor M'Fadyean, but he could detect nothing to account for the symptoms or fatal ending.

I 5 th March.-On this date a brown mare was found to be down and unable to rise; had her put in slings.

28th March.-Both mares still in slings. Bay mare losing flesh though eating well; pulse 60 , respirations 12 , temperature IOI $^{\circ} 6^{\circ}$. Brown mare's pulse 43 , respirations II, temperature $100^{\circ} 6^{\circ}$.

24th March.-At this date the condition of both animals had improved considerably; and the brown mare was thereafter put to plough for a short time daily, but placed in slings at night. I now ceased to attend the animals, but a few days later I learned that the bay mare had been found dead, the front rope of the slings having broken during the night, causing her to pitch forward on her head.

In conclusion I may say that while these animals were under treatment I was somewhat at a loss to know whether the symptoms were ascribable to simple inanition, or to some directly injurious effect of exclusive feeding on peas and pea straw. The loss of power was mainly in the hind quarters, and both rectum and bladder seemed to share in the paralysis. There was a marked absence of fever, and the appetite in the fatal cases was ravenous up to the last.

I may add, as a curious coincidence, that a short time afterwards I attended at another farm two mares with somewhat similar symptoms, but both of these were heavy in foal. They were placed in slings, and each duly gave birth while in the slings to a living foal. Both mares and foals subsequently did well.

\section{FOAL BORN WITHOUT FORE LIMBS.}

By W. P. Weston, M.R.C.V.S., Rutland.

PERHAPs the following case may prove interesting to some readers of the Journal.

During the first week of May of the present year, an iron-grey cart mare, belonging to a gentleman farmer, $\mathrm{Mr} \mathrm{H}$ $\mathrm{B}-$, in Kutlandshire, gave birth to a live healthy foal, which had only two legs.

These were the hind ones, the fore being entirely absent from the shoulder downwards. The foal would suck when held up to the mare, and was very lively and healthy.

After two days it was destroyed. On post-morten the scapula on either side was found to be well developed, except at the glenoid cavity, which on the right one resembled a tuberosity, and on the left was drawn into a fine point.

The skin over the chest and shoulders was perfect in every respect. 